\title{
Designing Online Information Aggregation and Prediction Markets for MBA Courses
}

\author{
Daphne R. Raban and Dorit Geifman \\ School of Management and the Center for the Study of the \\ Information Society, University of Haifa, Haifa, Israel
}

\author{
draban@gsb.haifa.ac.il; dgeifman@gsb.haifa.ac.il
}

\begin{abstract}
At our School of Management, novel Internet-based tools are employed in order to enrich the instruction of theoretical aspects of decision making with hands-on experience and expose the students to these unique tools. One example is the incorporation of online Information Markets that use the financial markets mechanism as an information aggregation and processing engine. In this case the underlying asset is a statement to be evaluated or an event to be forecasted. The resulting market price reflects the traders' collective opinion as to the event's probability of occurring or the statement to be corrected.

In class, three types of preconceived markets are implemented in order to expose the students to the versatility of the tool: prediction markets, information aggregation markets, and opinion markets. The hands-on activity was found to be essential for enhancing the understanding of this complex topic, and it added interest and excitement to the lessons. Furthermore, by surfacing opinions and attitudes of the students, this activity can assist in improving instruction processes and in-class dialogue. The development of an effective teaching environment required a substantial investment in time, but the direct monetary costs were relatively low.
\end{abstract}

Keywords: online simulations, information markets, prediction markets, wisdom of crowds, crowdsourcing, MBA course

\section{Introduction}

Educators, students, and employers often call for more intensive use of experiential instruction in higher education. While educators appreciate the pedagogical effectiveness of experiential learning, students and employees that take a more vocational perspective feel that graduates that are recruited by organizations are not well-enough prepared to cope with real-world challenges (Kolb, 1984). In a gathering of the Deans of the major business schools to mark the $100^{\text {th }}$ anniver-

Material published as part of this publication, either on-line or in print, is copyrighted by the Informing Science Institute. Permission to make digital or paper copy of part or all of these works for personal or classroom use is granted without fee provided that the copies are not made or distributed for profit or commercial advantage AND that copies 1) bear this notice in full and 2) give the full citation on the first page. It is permissible to abstract these works so long as credit is given. To copy in all other cases or to republish or to post on a server or to redistribute to lists requires specific permission and payment of a fee. Contact Publisher@InformingScience.org to request redistribution permission. sary of the Harvard Business School, critics of MBA programs claimed that business education is too theoretical and detached from the real needs of corporate managers (Thompson, 2008).

Internet technology introduces new teaching support tools that encourage active participation of students in the learning process. The computermediated learning environment touches on pedagogical paradigms, such as col-

\section{Editor: Alex Koohang}

An earlier, shorter version of this paper was presented at the Chais conference 2009, in Raanana, Israel, and included in Y. Eshet-Alkalai, A. Caspi, S. Eden, N. Geri, \& Y. Yair (Eds.), Proceedings of the Chais conference on instructional technologies research 2009: Learning in the technological era. Raanana: The Open University of Israel. http://www.openu.ac.il/research center eng/conferences.html 
laborative and experiential learning, and exposes the student to the practical aspects of the topics taught. The ease of use and accessibility of Wiki's, blogs, and other online collaborative tools facilitate rapid deployment of new forms of cooperative learning. The learner in such environments is engaged in a social constructivist mode of learning that facilitates a meaningful process of knowledge construction (Parker \& Chao, 2007). One way to reduce the gap between theory and practice in the field of management education is to incorporate computerized, networked tools such as business games, management simulations, and decision support tools as part of the curriculum (Rafaeli, Raban, Ravid, \& Noy, 2003).

This paper presents the development of three simulation-based instruction modules that use a novel internet-based decision support tool, known as Information Markets. These tools serve to enrich the teaching of decision making theory in MBA courses. Information markets are online environments that enable the aggregation of dispersed information needed by decision makers using a mechanism similar to that of financial markets. The online markets highlight the practical aspects of information collection, synthesis, and evaluation, and demonstrate the value of introducing experiential learning methods in adult education.

The paper starts with a brief description of decision making processes, which leads to the concept of the 'wisdom of crowds,' followed by a detailed description of online Information Markets as arenas for decision-making and information pooling. The next part presents the educational rationale that drives the development of tailored markets for in-class exercises. Finally, the paper provides a detailed description of the development process of the instruction modules, their outcomes, limitations, and plans for the future.

\section{Decision Making in Brief}

Business success often depends on the ability to make prudent decisions and judgments and to correctly anticipate future events. While early research on human judgment processes was based on the premise of rational choice, i.e., maximizing expected utility (Morgenstern \& Von Neumann, 1947) and Bayesian reasoning (Savage, 1954), Kahneman and Tversrky (1979) developed Prospect Theory which challenged these concepts. They showed that heuristics are used by individuals making judgments under uncertain conditions, leading to biases in the judgment outcome and producing decisions that deviate from rationality and are not optimal.

Intuition suggests that group deliberation by several people with diverse perspectives and information should better serve the decision process. Diversity coupled with intra-group interaction should reduce individual biases, but it has been shown that in complex and interesting problems group decision amplifies individual biases (Argote, Devadas, \& Melone, 1990; Bottom, Ladha, \& Miller, 2002; Burnstein \& Vinokur, 1977). The give-and-take nature of group discussion is expected to promote the pooling of knowledge to obtain a holistic picture. In many cases this was indeed the situation (Brown, 2000). Nevertheless this was not found to always hold up in reality. Group members may impose informational influences and social pressure on each other (Gigone \& Hastie, 1993). Irving Janis (1972), in his Groupthink model, suggested that in situations where groups are highly cohesive, operate under directed leadership, experience conditions of high stress, and perform limited search or appraisal of information, the group is likely to follow the judgment favored by the influential members. Additional methods, such as voting and polls, attempt to improve decisions by collecting information from very large groups. The next section introduces a more advanced, internet-based application of information aggregation from large and distributed groups. 


\section{Online Information Markets}

Information is an integral part of decision-making; however, the burden of collecting information is high. Searching, reading, comprehending, and applying information to decisions is often lacking due to limited resources such as time, money, or skills. The ubiquity of the Internet brings to the surface new ways of sharing and aggregating information, collecting opinions as well as individual knowledge into combined artifacts. This is possible by a new genre of applications and tools, such as wikis, blogs, and social networks, which are easily available and accessible and are designed to collect user-generated content. The book The Wisdom of Crowds (Surowiecki, 2004) outlined the conditions proposed for effective elicitation of the collective knowledge from a large group which focuses on alleviating information-related constraints:

1. Diversity - participants have different perspectives about the issue or question at hand.

2. Independence - participants possess independent information and are not inter-dependent by way of hierarchy or any other way.

3. Decentralization - participants do not communicate and influence each other.

4. Aggregation mechanism - there is a mechanism that combines all pieces of information into a one coherent entity.

Recently we are witnessing increased academic and business interest in the application of markets as a mechanism for information aggregation and decision support. Markets comply with the above four conditions of an efficient decision support tool while overcoming some of the shortcomings of the individual and group decision making methods.

Information Markets use the financial markets mechanism as an information aggregation and processing engine. In this case the underlying asset is a statement to be evaluated or an event to be forecasted. The price of the contract reflects the market opinion as to the event's probability to occur or the statement's chances to be correct. On the due date of the event, the market closes, the price of the stock that represents the actual outcome is fixed to the predefined amount, and all other stocks are nullified. The payoffs due to the traders are computed according to their holdings. These markets are implemented as an Internet-based system in the public domain (for example www.intrade.com and many others) or in an organizational environment (Cowgill, Wolfers, \& Zitzewitz, 2008; Hopman, 2007). Examples of typical questions resolved by markets are: Who will win the 2008 presidential elections? What will be the sales volume of product $\mathrm{X}$ in the last quarter of 2009? Will project Y be completed by December 2009?

Three different types of Information Markets are used to support decision processes:

- Information Aggregation Markets (IAM) - involve the collection of past information in order to solve a problem. In this case the uncertainty of the outcome results from a lack of knowledge. This lack of knowledge can originate from asymmetric information distribution among participants or from incomplete information, where people maintain only part of the required information (Page, 2007).

- Prediction Markets (PM) - evaluate future uncertain events (Wolfers \& Zitzewitz, 2004). In this case the outcome of the event can be affected by other unknown actions or events which have not yet occurred. This is the most common use of Information Markets, and often lends the name to the whole family of tools.

- Opinion Markets (OM) - process the subjective opinion of a group on a topic that does not have a deterministic outcome (Dahan, Lo, Poggio, Chan, \& Kim, 2006).

Information Markets of all three types incorporate a monetary incentive based on the performance of the trader. Economic gains for each player are proportional to the quality of the player's deci- 
sions expressed by 'buy' and 'sell' actions in the market. It is possible to lose money by "betting on the wrong horse". This structure encourages people to participate only if they have at least minimal knowledge of the topic, and it provides an incentive for disclosing true private knowledge. Due to anti-gambling regulations and budget limitations most markets use play money as incentive. Studies show that the use of play money does not diminish market accuracy (ServanSchreiber, Wolfers, Pennock, \& Galebach, 2004).

\section{Applying Information Markets in MBA Classes}

Academic management schools often base their raison d'être on three pillars: research, teaching of theory, and exposure of the students to state-of-the-art management processes and tools. Graduate and executive MBA programs combine theoretical instruction with practical experience in several ways: by incorporating the case teaching method, by assigning the students field projects, and by applying computerized simulations and games into the curriculum. Since the first introduction of the case method at the Harvard Business School in 1920 (Garvin, 2003) and the first business simulation game at the University of Washington 1957 (Watson, 1981), use of these experiential instruction methods has increased in the teaching of the business discipline, and its pedagogical value is well documented (Saunders, 1997). At the end of the previous century the penetration level of business simulation games into the American business schools reached 97.5\%, and business schools in other parts of the world were following (Faria \& Wellington, 2004). In some cases synergies between teaching and research can be found. These enhance the quality of instruction as well as feed into academic research (Noy, Raban, \& Ravid, 2006). To understand the importance and effectiveness of these experience-based teaching aids we turn to Kolb's experiential learning model.

Kolb (1984) models learning as a process where knowledge is created through the transformation of experience. This model describes a spiral that starts from Concrete Experience (CE), goes through Reflective Observation (RO) and Abstract Conceptualization (AC) and reaches Active Experimentation (AE), which leads again to concrete experience but from a different and more mature perspective (see Figure 1). Similarities can be found between this model and some models of problem solving, decision-making, and creative thinking, skills that are required of the modern manager. One example is Pounds' problem-solving process that flows through the phases of

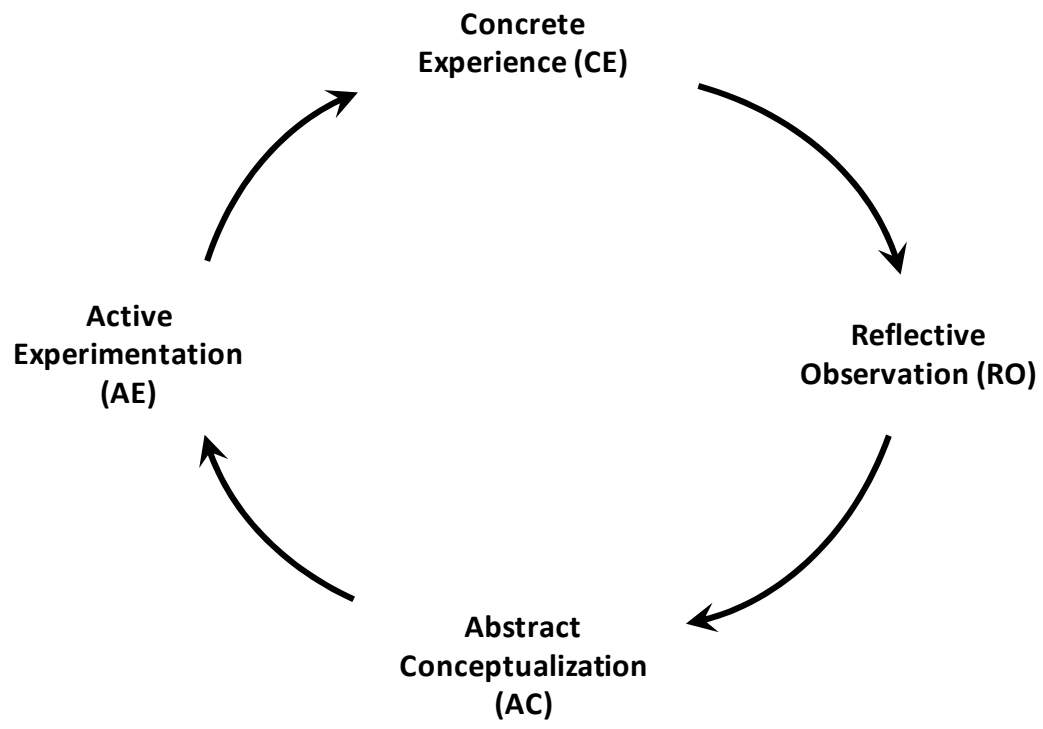

Figure 1: Kolb's experiential learning model. 
comparing the problem with reality, identifying differences, selecting a problem, considering alternative solutions, evaluating their consequences, selecting a solution, and executing it (Pounds, 1965). Other examples are Simon's decision-making model which goes through the phases of intelligence, design, and choice (Simon, 1947), and Wallas' creative thinking model which consists of preparation, incubation, illumination, and verification (Wallas, 1926). All these models describe a holistic and adaptive process that is the foundation for the continuous development of the personal cognitive capacity (Kolb, 1984). Managerial decision processes are not only complex, they also involve varying levels of risk and may have negative implications for the organization and for employees. It is therefore natural to seek lower risk, experiential learning methods, e.g., the case studies, simulations, and games that provide profound learning experience at relatively low cost and at no risk to real organizations and real people.

Business and management theories are complex because they try to describe complex processes that occur in parallel or are inter-dependent and originate in several different knowledge domains such as accounting, marketing, and human resource management. Understanding these complex systems involves conceptual models and contingent and behavioral theories. The use of simulations and games was found to significantly assist in overcoming the difficulties of conveying complex theoretical ideas and internalizing the learning experience in MBA classes. These methods well suit managers and executives who are assumed to be more competitive, exhibit a practical personality and behavior, and tend towards an active experimentation learning style (Rafaeli et al., 2003). Buzzetto and Mitchell (2009) claim that web-based competitive simulations may serve as equalizers, offering both low and high achieving students the opportunity to succeed. They show that minority and academically under-prepared students that participate in management courses exhibit improved performance and satisfaction after they experience business simulations.

Games and simulations comply with the modern student-centered instruction paradigm which is at the root of experiential learning. They offer the learners a rich perspective of the topics being studied through reference to the workplace environment and the opportunity to experience the dynamics of the business conditions (Saunders, 1997).

Online Information Markets can be classified as simulations since they use real market mechanisms, and the students act as traders in a real-world environment. The markets serve as a platform which deploys a story-line that is made up by the instructor to suit the purpose of the curriculum. Such markets have unique advantages for MBA classroom instruction as they are:

- A unique example for knowledge sharing between people,

- An example for an information aggregation and prediction mechanism,

- A good platform for understanding markets and incentives,

- A good platform for understanding behavioral aspects in knowledge sharing and decision making under uncertainty,

- A novel extension to the arsenal of decision support tools.

In class the hands-on activity in online Information Markets is preceded by a lecture accompanied by a presentation. The lecture explains a variety of advantages and problems in decision making at the individual and group level leading up to novel idea of 'wisdom of crowds.' The Markets are used to demonstrate this idea as well as to offer the unique decision support tool. Combining theoretical instruction with actual trading is expected to:

- Introduce a practical flavor to the theoretical instruction,

- Improve the understanding of the underlying theory, 
- Add motivation, attention, excitement, and interest to the lesson,

- Expose the learners to a novel tool which they can further implement at their workplaces,

- Involve all students in active learning.

Sometimes the simulations and games used for teaching may also serve the school's research agenda (Noy et al., 2006). Researchers who employ experimental methods can be involved in the design and implementation of the learning module and contribute to its quality. The insights derived from the simulation data and the observation into its dynamics feed into future versions of the module design. The researcher on the other hand, gains access to controlled experimental data.

In the following we describe how Information Markets are woven into courses and help in teaching various aspects of decision making including the behavioral dimension.

\section{The Development of the In-Class Activity}

In class, Information Markets and decision making theory teaching is complemented with a hands-on experience of trading in preconceived markets. The activities are designed to address the lesson objectives, and the topics of trading are aligned with the focus of the specific MBA program. The markets are set up on a commercially available platform (www.inklingmarket.com)

The students are asked to fill in a brief questionnaire prior to trading. This questionnaire is used mainly for research purposes. After the market trading activity the students are asked to fill in a questionnaire regarding their impressions of the effectiveness of the tool and the difficulty in performing the activity. The outcomes of the post-trading questionnaire are used to improve the activity.

The following sections will outline three different modules of Information Market activity; each implements a different market type and is incorporated in a different course. A review of activity development considerations and lessons learned follows. This part of the paper will conclude with the result of a feedback questionnaire that was presented to the students.

\section{Information Aggregation Market - The Hidden Profile Task}

The Hidden Profile Task is an assignment in which segments of partial information are distributed among several participants, but when all information is collected, a complete and certain picture is obtained (Stasser \& Titus, 1985). We employ an Information Aggregation Market to collect the partial information and combine it into a specific outcome.

The students are presented with a crime scenario and details about 6 suspects, including the villain. A market, named Fantasia, with six stocks, each representing a suspect, is set-up. Each student receives private information that consists of an alibi for one or more of the suspects. The exercise is designed in a manner so that if all private information is combined, the guilty person can easily be identified. The students are instructed to buy the stocks of the suspects they believe might be guilty and sell stocks of suspects they believe are innocent. The market runs for 20 minutes, and during this time the students are not allowed to talk with each other. When the market closes the stock representing the villain is expected to achieve the highest price. The incentive scheme consists of a modest prize (e.g., a book) for the student who achieves the highest account balance.

The market prices timeline chart in Figure 2 reflects the change in market opinion regarding the identity of the villain during the 20 minutes of trade. 


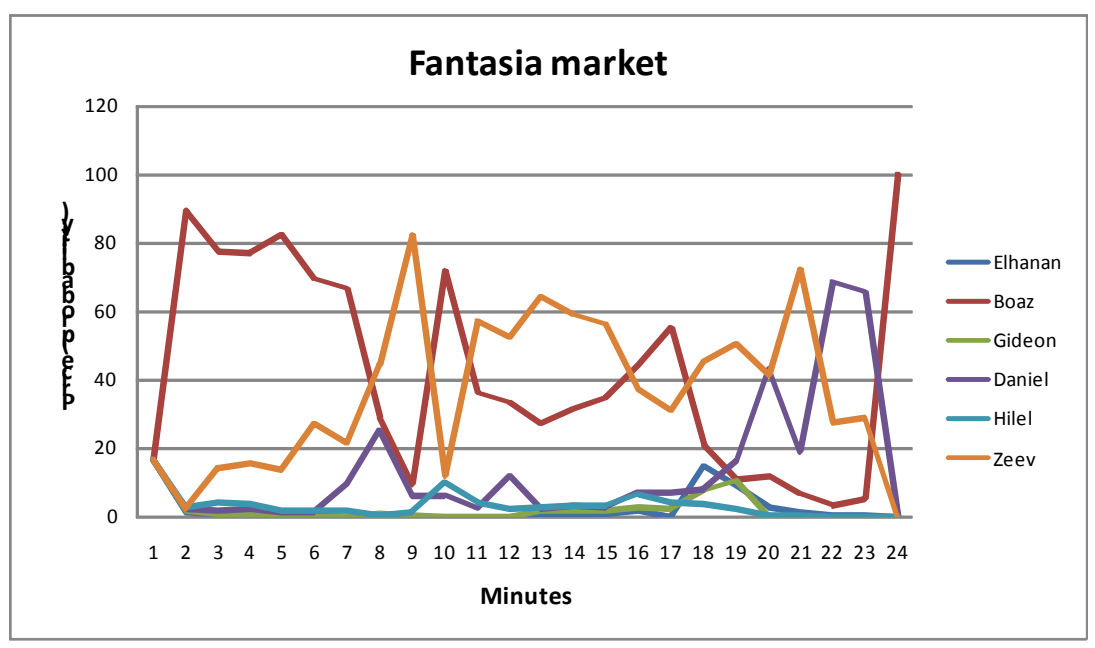

Figure 2: Hidden Profile Task - market trading chart

The activity was performed in several classes. Only one group correctly identified the guilty suspect at market closing. In other cases the correct answer was identified close to the beginning of trade but then trading drifted and the final outcome was not the correct one. Nevertheless the incorrect outcome was useful for demonstrating various behavioral phenomena. This will be further elaborated in the Discussion section.

\section{Prediction Markets - Business Simulation Game}

This scenario is introduced as a complementary, voluntary activity in the business simulation game course that takes an entire term in the MBA program. In this business game students are charged with managing firms competing in a virtual "world". The students work in competing teams, each responsible for operating one firm for several game "years" and the team that achieves the highest shareholder value by the end of the last year wins the game. There are two main periods in the game. In the first few years each group of students operates in a single-firm mode as part of a competitive market. The team members experience the various aspects of managing a firm. On the fifth year the option of mergers \& acquisitions is activated, and the students experience additional skills such as negotiation and management of multi-firm corporations. The business game is characterized by an intense atmosphere of activity and competition.

A Prediction Market is set up to predict the winning team. The markets open on the last year of the single-firm stage and close a few hours before the final game results are published. The students, who are players and concurrently Prediction Markets traders, trade under conditions where they have a certain perceived sense of influence on the outcome.

In order to maintain interest, and increase activity and participation in the marketplace, every week supplementary events addressing intermediate results of the game as well as events that relate to general current events are defined. The incentive scheme consists of two prizes: one for the student who achieves the highest account balance when the markets close, the other a participation prize based on a draw.

The market prices timeline chart in Figure 3 outlines the average daily market price of each team during the trading period. The price reflects the market prediction of the winning firm. Each vertical line indicates the end of a virtual year. 


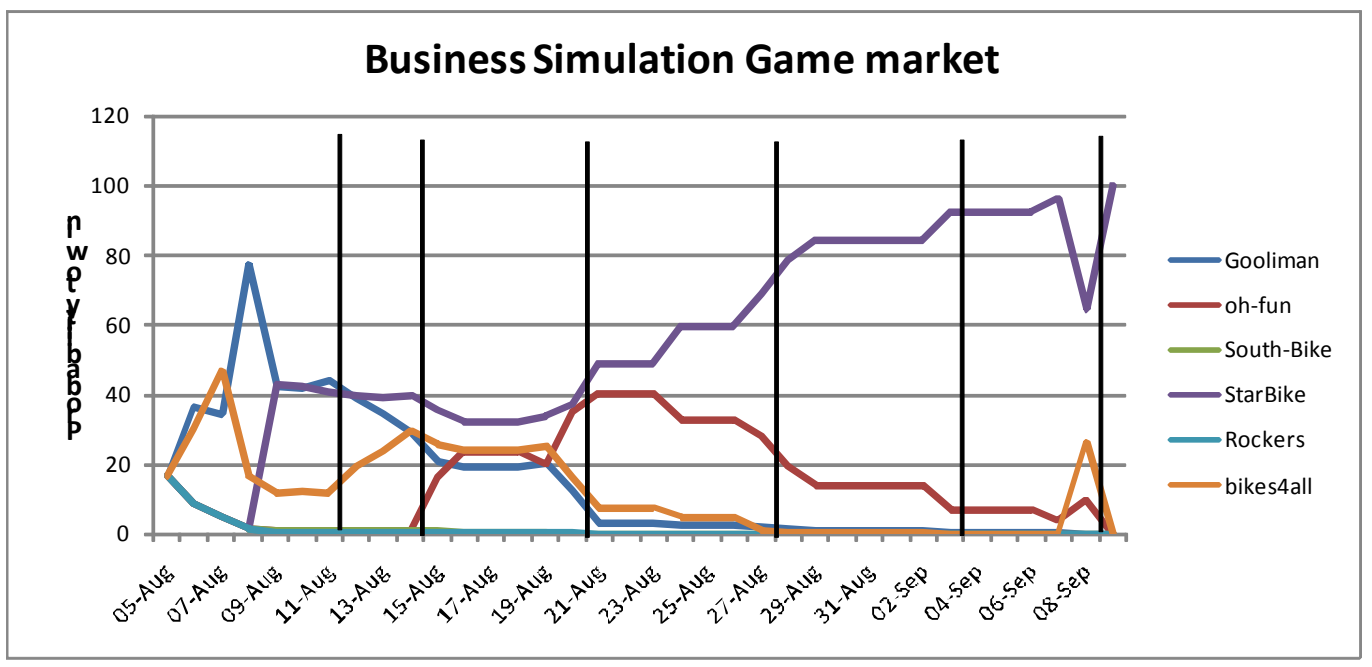

Figure 3: Business Simulation Game - market trading chart

The markets were run in three MBA classes. 38 out of 114 students participated in trading, representing 18 out of the 20 firms. All the students were previously exposed to the concept of Information Markets, but only one of the classes had participated in the Hidden Profile Task market which is described above. Two out of the three markets identified the game winner correctly.

\section{Opinion Market - Reducing the Economic Divide}

Policy makers can augment the democratic process by using Opinion Markets to elicit the opinion of a large and distributed constituency. The markets can be used to identify the public preference regarding legislation, civilian projects, etc. (Hahn \& Tetlock, 2003). The concept of online Opinion Markets in the public sector is aligned with the objectives of our MBA program for managers of non-profit organizations. For students in this program we modified the hands-on activity that accompanies the theoretical teaching of Information Markets to be based on Opinion Markets.

The scenario was about a recent issue that was often reported in the news: the publication of new economic indices that exhibited an increase in economic inequality between the rich and the poor. An intense public debate started regarding the measures that should be taken in order to decrease the economic divide. Three measures were proposed:

- Increasing the government-funded child support.

- Introducing a negative income tax. This means that workers that do not reach a minimum level of income will be compensated by the government.

- Government intervention for increasing economic growth.

Each proposed measure was the subject of one market where the stocks traded were for or against one of the measures listed above. The price of the stock represents the level of group support for the specific measure. The approach of three separate markets was chosen as the three methods are not assumed to be mutually exclusive.

The students were handed background material describing the pros and cons of each measure and were asked to read it in class. Once they completed this task the marketplace opened for trading. While trading went on, an open discussion on the effectiveness of the different measures took place in class. It should be noted that in this type of market the price represents the group's consensus as there is no objective "truth" which can be used to resolve the market. Consequently the activity relied on intrinsic motivation for participation and true disclosure of opinion. 
Figure 4 compares the market price that corresponds to the level of support of the three measures during the overall trading period. The chart shows the change in group opinion during the discussion. The consensus eventually settled on applying government growth measures as the best method to deal with the increasing economic gap. Although each method was implemented by a separate market, a relationship between the levels of support of the three methods is evident from the chart.

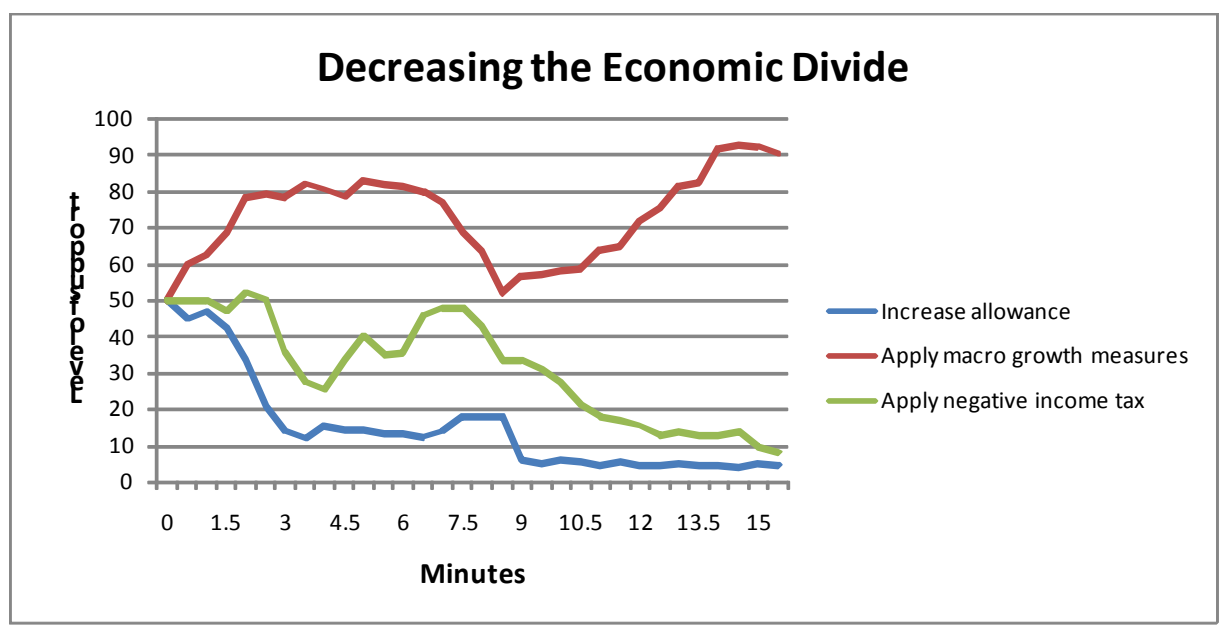

Figure 4: Decreasing the Economic Divide - market trading chart

This module is still in the development process and to date has been performed in one class only (31 students).

\section{Reflection on Considerations and Lessons Learned}

The development of the online Information Markets activity is an ongoing process. The initial considerations were based on theory and insights that are available in academic and business literature and were cited earlier. Problems and observations that were encountered during the lessons were analyzed and integrated into subsequent versions of the activity. This section outlines some of the design considerations and findings.

The following advantages encouraged us to use one of the commercially available online platforms to host the markets:

- A stable environment for designing and running custom markets, enabling the designer to focus on the content rather than technical aspects of the activity.

- Commercial platforms provide a user-friendly interface that hides the complexity of the trading process from the non professional trader.

- The students are exposed to new tools that they can further explore and use in their workplace.

- The vendor provided us with a private, password protected, area. Personal anonymity and data security were thus ensured.

- The entire activity logs were made available to us for analysis.

Learning Curve: During the pilot runs we found that some of the students had difficulty understanding the trading procedures. Consequently for each instruction module we have developed tailored training markets similar in structure to the scenarios in the module. We have also devel- 
oped a detailed training kit. Currently the students practice with the training markets before they proceed to the main exercise.

Market Design: Variations to the market design were required for the different instruction modules and teaching contexts. The longer period of trading in the Business Simulation markets require that we implement additional short-term markets in order to keep the span of interest in the activity. In order to maintain the relevance of the activity, the topics that are traded in training and supplementary markets need to be adjusted to the focus of the specific program or current events.

Trading Duration: The different instruction modules require the fine-tuning of the length of the trading period. For example, in the Hidden Profile Task module the students obtain all taskrelated information by reading the crime scenario before trading starts. During the trading period the only new information arrives from market signals. We noticed that after 6-8 minutes of trading the students' focus shifts from the task of aggregating information to a game-like competition and manipulation that causes the market price to go astray. This trading pattern which was evident in several markets and demonstrated in Figure 2 was also confirmed during class discussion. The duration of the Opinion Market was adjusted to class discussion time, while the duration of the business simulation game markets was dictated by the game schedule.

Trading Patterns: As part of the trading process the trader is expected to buy stocks that state events with which she agrees and sell the stocks that represent statements which she thinks are false. We noticed that students in general are less inclined to sell stocks. They are especially reluctant to sell stock which they do not possess (short-selling). To partly overcome this bias we changed the initial endowment scheme and each student received an initial amount of stocks in addition to the initial monetary allowance.

Incentives: The correct planning of the incentive scheme is crucial for the success of the market. Due to different characteristics of the markets in each module a different incentive scheme was designed. The Hidden Profile Task market is a short period market that is run during class. In this case the reward is a performance based prize. The student with the highest account balance after market resolution receives the prize. The Business Simulation market runs for a long period: a few weeks. In this case an additional lottery-based participation reward was granted in order to encourage ongoing participation. The lack of an objective true result in the case of Opinion Markets disables the resolution of these markets. Consequently in the Reducing the Economic Divide module we communicate the importance of internal motivation to the success of the activity. This was possible to do since this was a short in-class activity.

The outcomes and the strengths and weaknesses of the various activities are summarized in the Discussion.

\section{Activity Feedback Questionnaire}

As part of the Hidden Profile Task activity the students are presented with a feedback questionnaire. This questionnaire explores students' impressions and opinions regarding the tool and the activity once they have experienced it. The students fill in this 'satisfaction' questionnaire before the markets are resolved with the correct information. The satisfaction responses are used as input for the activity evaluation and improvement process.

Seven markets were administered in 5 classes. Overall, 100 students participated in the activity, of whom 98 filled the questionnaire. Some questionnaires were only partially filled, resulting in a sample size of 80 responses per question.

Table 1 summarizes the students' feedback (post activity questionnaire). One-way ANOVA was performed in order to check whether there were differences among various classes. No statisti- 
cally significant difference ( $\mathrm{p}>.05$ ) was found. Consequently data was combined for further analysis. Descriptives are shown in Table 1.

Table 1: Results of the post activity questionnaire

\begin{tabular}{|l|l|l|}
\hline & Mean & SD \\
\hline Trading improved my confidence in my opinion & 4.02 & 1.75 \\
\hline $\begin{array}{l}\text { My trading was motivated by the willingness to solve the } \\
\text { problem }\end{array}$ & 4.24 & 1.764 \\
\hline $\begin{array}{l}\text { My trading was motivated by the willingness to win the } \\
\text { game }\end{array}$ & 5.42 & 1.424 \\
\hline I had difficulty in coping with the system & 3.27 & 1.718 \\
\hline I found the activity to be interesting & 5.84 & 1.257 \\
\hline $\begin{array}{l}\text { Information Markets can be used as an effective decision } \\
\text { support tool }\end{array}$ & 4.94 & 1.586 \\
\hline
\end{tabular}

( $1=$ do not agree, $7=$ agree), $\mathrm{N}=80$

\section{Discussion}

This paper presents the fruit of a process of development of an experiential learning activity that is multifaceted and lends itself to many applications. In fact, the complexity of development corresponds to the complexity of managerial decision making and is reflected in the fine-tuning required in terms of type of question asked, market structure, duration, incentives, and so on.

The characteristics of online Information Markets position them as realistic simulation tools that well support the cognitive process of experiential learning as modeled by Kolb (Gunz, 1995). Gunz presents a tension between simplicity, which is instrumental for learning, and complexity, which better serves realism. In the present case, the markets are simple enough when adequate training and practice are given. Yet, the markets are also realistic since they are already implemented in corporations and are quite widely used freely on the web. Simplicity is achieved when markets are well defined and address precise and clear questions or issues. The concept of trading information assets is not straightforward and needs to be internalized by teaching, support materials, and hands-on training. But once the concept is mastered, the technical proficiency that is required in order to perform well in the market is not a barrier. The major challenge facing the students in this environment is to focus on their knowledge and the information at their disposal and execute the appropriate trading transactions. This involves dealing with uncertainty and sometimes changing conditions, comparing this decision with market conditions, and adjusting earlier decisions.

The iterative nature of trading creates for the learner (the trader) an operational environment that resembles the different stages in the Kolb model. The trader reflects on the information at her disposal and makes an initial decision which she can apply by trading stocks. Next, the trader observes the evolving market price and reflects on its meaning with respect to her own opinion. The trader then assimilates the information and conceptualizes it into her preferred action (buy, sell, or do nothing). This leads to the actual experimentation stage, which is the execution of a market transaction. The result of this action combined with those of the other traders, as reflected through the new market price, triggers a new trading cycle. Further, the presence of conflict, which is recognized as an important contributor to effective learning, is inherent to the activity. Conflict appears in two forms. The first is the need to position one's own opinion with respect to the market signals. Opinion and market signals do not always align. The other aspect of conflict stems from the competitive nature of the activity. The similarities between the student's actions in 
the market environment and the underlying concepts of learning lead to the assumption that this kind of activity positively contributes to the quality of learning.

Selling and buying patterns were analyzed in the class discussion that followed trading activity. Not all markets demonstrated the expected behavior, but these were the markets that stimulated the more interesting discussions. Two well-known decision flaws emerged and were discussed in class. (1) The cascading effect, a known effect in market bubbles (Shiller, 2002) whereby past price increases feed back into the market as a signal for further demand that boosts additional price increase. This increased demand is not grounded in economic justification but is derived from traders' judgment biases. The cascading effect was identified in our markets when an abrupt stock price increase, caused by an intense activity of one or two traders, triggered further demand of this stock and increase of its price. Some of the traders that caused this bubble effect admitted that the action was driven by the change in market price and not by a new information, knowledge or opinion. It should be noted that this effect was amplified due to the small number of traders in the market. (2) The negativity bias, where individuals find negative information more influential in forming their impression than positive information (Skowronski \& Carlston, 1989), and stereotype-matching filtering of information, where people maintain their pre-existing stereotypic belief despite disconfirming information (Johnston, 1996; Stewart, 1998), were evident in the Hidden Profile Task. It turned out that a few students bought stocks of a suspect that was described in the scenario basing their decision on a negative stereotype, thus demonstrating their belief in his guilt, although they received an alibi for this suspect. Complementing the theoretical teaching with a hands-on experience assisted in internalizing of the theoretical concepts. The students were confronted with their own biases and performance limitations and can further use this recognition to improve their skills. In this way the school objective of bridging the gap between theory and practice is also met.

As part of the activity the students were asked to fill in questionnaires regarding their impressions of the effectiveness of the tool and the difficulty in performing the activity. The results in Table 1 indicate that not all students perceived the tool as effective in providing them confidence in their decisions and in assisting them with their task of problem-solving. Yet the students understood the potential of the tool for decision making and found the activity interesting. In contrast to the normative expectation that the students would be motivated by their willingness to reach a correct decision, most students were motivated by their willingness to play and win the game. Possibly, competition may have attracted too much attention suggesting that future applications of Information Markets should incorporate more than a single, competitive incentive for participation. Another option is to design partial or contingent incentives. Partial incentives include, for example, a draw of several token prizes for several participants regardless of their achievements. Contingent incentives are such that a player will receive the award if $\mathrm{s} /$ he passes a certain level of participation or a certain threshold of achievement. Overall, students found the activity interesting, relevant, and reasonably easy for MBA students.

In the case of the Business Simulation Game module, online Information Markets assisted in improving teaching processes by surfacing opinions and attitudes of the students towards the instruction process and content. Experience shows that in most cases, once the side-effects of the merger \& acquisition actions settle down (after a 'year' or two), the identity of the winning team is finalized and will not change in the remaining periods of the simulation. Market results showed that that the students have anticipated this course of events prior to the end of the game. In subsequent classes we took measures to extend the competitive atmosphere to later stages in the game in order to maintain tension and interest.

Beyond the teaching and learning goal achieved, the activity described in this paper contributes to the research agenda of the School of Management. The opportunity to run multiple markets in different configurations provides the School's researchers with a good research platform for ex- 
perimental research. The questionnaire data from before and after trading combined with the trading logs available online enable the further study of phenomena that are identified in these markets and substantiate various theories in this field.

Last but not least, similar use of Information Markets can be found in the corporate environment. Corporations such as Hewlett-Packard, Intel, and others are developing and applying Information Markets toward their business goals (Chen \& Plott, 2002; Hopman, 2007). For example, Prediction Markets run by Google enabled the tracking of information flows around the organization by correlating proximity in traders' market positions and physical office locations. Employees' trading patterns also provide an insight as to how employees react to external events that were traded in the markets (Cowgill et al., 2008). These accounts of prior corporate application were conveyed to the students in order to raise their interest and demonstrate the practical side of this learning experience.

\section{Limitations}

The teaching of online Information Markets is incorporated in the curriculum of courses that deal with virtual communities and competitive intelligence. In these courses we teach about online social and collective intelligence tools such as wikis, blogs, online idea generation, and online decision support. Information Markets and other social Web 2.0 tools empower the individual and benefit the community. Unfortunately, the potential of online Information Markets was not fully realized in the scenarios that were used in class so far. For example, in the Hidden Profile Task activity several markets did not exhibit the expected outcome, i.e., identifying the villain in the Fantasia case. The explanation lies in two main issues that need to be addressed in future development: the small number of market participants and the duration of the markets (see discussion above). In the post-trading questionnaire the students reported that trading in the market improved their confidence in their opinion and that Information Markets can be used as an effective decision support tool. However these results point to the fact that a number of students were under the impression that trading did not contribute to their personal decision-making capacity. This should be addressed in future development of activities that preclude information cascades, stereotypes, and the negativity bias as well as by developing more elaborate incentive systems.

Information Markets are a novel tool, and their effectiveness as a prediction and decision support tool is still studied by the academic and business communities. The students were aware that they were experimenting with a new tool and concept. They appreciated the fact that while the outcome of the markets was not always as expected, they could still gain personal insight and handson experience regarding information processing and decision-making patterns and about how individual behavior affects the collective outcome of the group.

\section{Conclusion}

The availability of the Internet platform and the abundance of new off-the-shelf applications offer new opportunities to enhance the theoretical teaching with practical experience. It is now easier to introduce new methods for changing and improving the instruction process. These new educational methods will help the students cope with the practical challenges awaiting them at the workplace. They can also provide students with ideas for implementation in corporate training.

This paper highlighted the incorporation of online Information Markets in the MBA curriculum as a way by which information becomes the main issue and the main object of the markets. The process of trading in Information Markets resembles the cognitive model of Kolb's experiential leaning. Consequently the nature of the activity is expected to contribute to a meaningful and effective learning process. 
Even though the expected potential of this tool was not fully realized in class, the objectives that motivated the introduction of the online Information Markets activity were achieved. The activity surfaced significant biases in group decision making processes and information processing, and the students gained valuable insight into their own decision making patterns. The hands-on activity helped to enhance the understanding of a complex topic and added interest and excitement to the lessons.

It is important to note that while the technical deployment of Internet based educational tools is easy and involves a relatively low monetary cost, an effective implementation of computer-based learning module requires considerable methodological attention and is time consuming. Web2.0 software by definition is an empty platform. Its value and importance stems from content contributed by individual users. This is also true for online Information Markets as an educational platform. Fundamentally the markets form an empty and flexible platform that can be taken up by educators in any program, be it information studies, economics, management, decision making or others. The quality, value, and effectiveness will only be limited by the skills and creativity of the designers of the learning activities.

\section{Acknowledgement}

The authors wish to thank Inklingmarkets.com for their continued support of the Prediction Markets activity in our school

\section{References}

Argote, L., Devadas, R., \& Melone, N. (1990). The base-rate fallacy: Contrasting processes and outcomes of group and individual judgment. Organizational Behavior and Human Decision Processes, 46(2), 296-310.

Bottom, W. P., Ladha, K., \& Miller, G. J. (2002). Propagation of individual bias through group judgment: Error in the treatment of asymmetrically informative signals. Journal of Risk and Uncertainty, 25(2), 147-163.

Brown, R. (2000). Group processes: Dynamics within and between groups Blackwell Publishing.

Burnstein, E., \& Vinokur, A. (1977). Persuasive argumentation and social comparison as determinants of attitude polarization. Journal of Experimental Social Psychology, 13(4), 315-332.

Buzzetto-More, N., \& Mitchell, B. C. (2009). Student performance and perceptions in a web-based competitive computer simulation. Interdisciplinary Journal of Knowledge and Learning Objects, 5, 73-90. Retrieved from http://ijello.org/Volume5/IJELLOv5p073-090Buzzetto654.pdf

Chen, K. Y., \& Plott, C. R. (2002). Information aggregation mechanisms: Concept, design and implementation for a sales forecasting problem. Lee Center Workshop.

Cowgill, B., Wolfers, J., \& Zitzewitz, E. (2008). Using prediction markets to track information flows: Evidence from Google. Dartmouth College. Retrieved from http://www.bocowgill.com/GooglePredictionMarketPaper.pdf;

Dahan, E., Lo, A. W., Poggio, T., Chan, N. T., \& Kim, A. (2006). Securities trading of concepts (STOC). University of California at Los Angeles, Working Paper.

Faria, A. J., \& Wellington, W. J. (2004). A survey of simulation game users, former-users, and never-users. Simulation \& Gaming, 35(2), 178-207.

Garvin, D. A. (2003). Making the case: Professional education for the world of practice. Harvard Magazine, $106(1), 56$.

Gigone, D., \& Hastie, R. (1993). The common knowledge effect: Information sharing and group judgment. Journal of Personality and Social Psychology, 65(5), 959-974. 
Gunz, H. P. (1995). Realism and learning in management simulations. Journal of Management Education, 19(1), 54.

Hahn, R. W., \& Tetlock, P. C. (2003). Using information markets to improve public decision making. AEIBrookings Joint Center Working Paper, (04-18).

Hopman, J. W. (2007). Using forecasting markets to manage demand risk. Intel Technology Journal, 11(2).

Janis, I. L. (1972). Victims of groupthink. Houghton Mifflin Co.

Johnston, L. (1996). Resisting change: Information-seeking and stereotype change. European Journal of Social Psychology, 26, 799-825.

Kahneman, D., \& Tversky, A. (1979). Prospect theory: An analysis of decision under uncertainty. Econometrica, 47(2), 263-291.

Kolb, D. A. (1984). Experiential learning: Experience as the source of learning and development. Englewood Cliffs, NJ: Prentice-Hall.

Morgenstern, O., \& Von Neumann, J. (1947). Theory of games and economic behavior. J. Wiley and Sons.

Noy, A., Raban, D. R., \& Ravid, G. (2006). Testing social theories in computer-mediated communication through gaming and simulation. Simulation \& Gaming, 37(2), 174.

Page, S. E. (2007). The difference: How the power of diversity creates better groups, firms, schools, and societies. Princeton, NJ, USA: Princeton University Press.

Parker, K. R., \& Chao, J. T. (2007). Wiki as a teaching tool. Interdisciplinary Journal of Knowledge and Learning Objects, 3, 57-72. Retrieved from http://ijello.org/Volume3/IJKLOv3p057-072Parker284.pdf

Pounds, W. F. (1965). The process of problem finding. Working Paper, Massachusetts Institute of Technology, Sloan School of Management, Paper No. 145-165.

Rafaeli, S., Raban, D. R., Ravid, G., \& Noy, A. (2003). Online simulations in management education about information and its uses. In C. Wankel \& B. DeFillippi (Eds.), Educating managers with tomorrow's technologies (pp. 53-80) Information Age Publishing, Inc.

Saunders, P. M. (1997). Experiential learning, cases, and simulations in business communication. Business Communication Quarterly, 60(1), 97.

Savage, L. J. (1954). The foundation of statistics. New York: J. Wiley and Sons.

Servan-Schreiber, E., Wolfers, J., Pennock, D. M., \& Galebach, B. (2004). Prediction markets: Does money matter? Electronic Markets, 14(3).

Shiller, R. J. (2002). Bubbles, human judgment, and expert opinion. The Financial Analysts Journal, 58(3), 18.

Simon, H. A. (1947). Administrative behavior. New York: Macmillan.

Skowronski, J. J., \& Carlston, D. E. (1989). Negativity and extremity biases in impression formation: A review of explanations. Psychological Bulletin, 105(1), 131-142.

Stasser, G., \& Titus, W. (1985). Pooling of unshared information in group decision making: Biased information sampling during discussion. Journal of Personality and Social Psychology, 48(6), 1467-1478.

Stewart, D. D. (1998). Stereotypes, negativity bias, and the discussion of unshared information in decisionmaking groups. Small Group Research, 29(6), 643.

Surowiecki, J. (2004). The wisdom of crowds: Why the many are smarter than the few and how collective wisdom shapes business, economies, society and nations. New York: Doubleday.

Thompson, R. (2008). Harvard business school discusses future of the MBA. Retrieved from http://hbswk.hbs.edu/item/6053.html

Wallas, G. (1926). The art of thought. New York: Harcourt Brace. 
Watson, H. J. (1981). Computer simulation in business. New York: John Wiley \& Sons.

Wolfers, J., \& Zitzewitz, E. (2004). Prediction markets. Journal of Economic Perspectives, 18(2).

\section{Biographies}

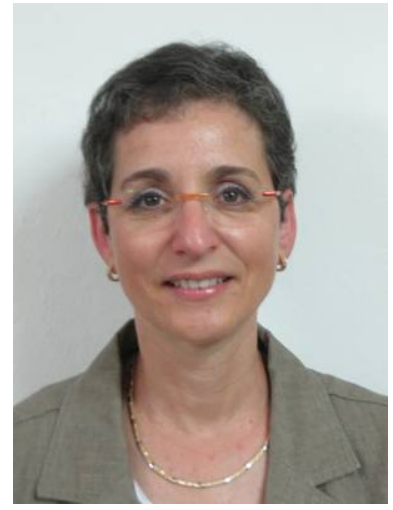

Daphne R. Raban received her Ph.D., Summa Cum Laude in 2004 from the U. of Haifa and was honored by Emerald/EFMD Outstanding Doctoral Research Award in the category of Enterprise applications of internet technology (2006). In December 2002 she received the Roger $\mathrm{K}$. Summit scholarship for her academic and professional achievements. Her research interests are in economics of information goods, information/knowledge sharing, the interplay between social and economic incentives, and in games and simulations. Dr. Raban has published in refereed information science journals and teaches online competitive intelligence, virtual communities, and information economics in MBA programs. She is a lecturer at the School of Management in the University of Haifa and an active member of the Center for the Study of the Information Society (U. of Haifa) and professional associations: AoIR, AIS/ILAIS, SCIP, and ISOC-IL.

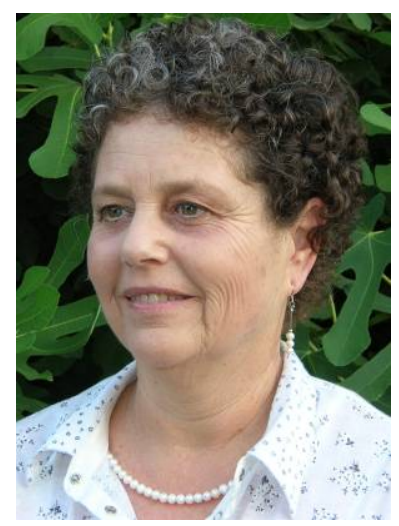

Ms. Dorit Geifman is a PhD student at the Graduate School of Management, University of Haifa, Israel. She received her M.Sc. in Computer Science from the Weizmann Institute of Science, Rehovot, and a B.Sc. with distinction in Mathematics and History and Philosophy of the Science from the Hebrew University, Jerusalem. Ms. Geifman's research interest is in crowdsourcing and specifically in judgment biases in Information Markets. Ms. Geifman is an instructor in business simulation games for graduate students and executives that take place at the Graduate School of Management and is active at the Center for the Study of the Information Society, University of Haifa. 